\title{
Fusarium oxysporum f. sp. lycopersici race 3 causing tomato wilt in South Africa
}

\author{
A. Jacobs $•$ R. Govender $\cdot$ S. W. van Heerden
}

Received: 5 August 2013 / Accepted: 14 October 2013 / Published online: 26 October 2013

(C) Australasian Plant Pathology Society Inc. 2013

\begin{abstract}
In 2010, tomato plants exhibiting symptoms of wilting, hollow stems and vascular discoloration from the Musina district, Limpopo Province, South Africa were reported. Fusarium oxysporum f. sp.lycopersici race 3 proved to be a causal agent of the disease by means of morphological and DNA based characterization accompanied by pathogenicity trials. This is the first report of Fusarium oxysporum f. sp. lycopersici race 3 on tomato in South Africa.
\end{abstract}

Keywords Tomato · Fusarium oxysporum f. sp. lycopersici race 3 . South Africa

Tomato is an economically important vegetable crop in South Africa. It is commonly grown by subsistence and resource poor farmers and serves as one of the main vegetables used for hawking by small-scale entrepreneurs in the informal sector. The total production areas are estimated at more than 5, 400 ha. Approximately 100 ha of this area consists of production under protection (tunnels and greenhouses).

Fusarium oxysporum is an abundant, asexual fungal species complex with numerous morphologically indistinguishable plant pathogenic strains associated with a range of vegetable and other crops. Based on the host plant and cultivar specificity $F$. oxysporum strains have been grouped into formae speciales and races, respectively (Armstrong and Armstrong 1981; Di Pietro et al. 2003;

\footnotetext{
A. Jacobs $(\bowtie)$

Mycology Unit, Biosystematics Division, Plant Protection Institute, Agricultural Research Council, Private Bag X134, Queenswood, Pretoria 0121, South Africa

e-mail: JacobsR@arc.agric.za

R. Govender $\cdot$ S. W. van Heerden

Sakata Vegenetics RSA (Pty) Ltd, P.O. Box 160, Lanseria 1748, South Africa
}

Michielse and Rep 2009). In 2010, tomato (Solanum lycopersicum ) plants exhibiting symptoms of wilting, hollow stems and vascular discoloration from the Musina district, Limpopo Province, South Africa were analysed Fig. 1.

Stem tissue was surface disinfected with $70 \%$ ethanol and placed on potato dextrose agar (15 g/1) containing Streptomycin $(0.4 \mathrm{~g} / \mathrm{l})$ and incubated in the dark at $25^{\circ} \mathrm{C}$ for 7 days. Morphological characterisation of the selected isolate (Plant Protection Research Institute, PPRI 10733) was done on a 10 day old culture grown on Carnation leaf agar (Leslie and Summerell 2006). The single-spored isolate, PPRI 10733 has been deposited in the National Collections of Fungi, PPRI Collection, Plant Protection Research Institute, Agricultural Research Council, Pretoria, South Africa. The identity of the selected isolate was morphologically confirmed as Fusarium oxysporum (Nelson et al. 1983). For molecular analyses the isolate was grown in complete medium broth at $25^{\circ} \mathrm{C}$ in the dark for 7 days. DNA was extracted using the DNAeasy Plant Mini extraction kit (Qiagen), followed by PCR and sequencing of the partial translation elongation factor- $1 \alpha$ (TEF- $1 \alpha)$ gene (O’Donnell et al. 1996). Obtained sequences were compared with those on the NCBI, Fusarium MLST (O'Donnell et al., 2012) and FUSARIUM-ID databases (Geiser et al. 2004). In all three of these independent BLAST analyses the isolate matched strains of $F$. oxysporum f. sp. lycopersici, with statistical significance. This was confirmed by a phylogenetic analysis of the partial TEF-1 $\alpha$ gene data, which clustered the unknown isolate together with a $F$. oxysporum f. sp. lycopersici strain with the same mating Fig. 1 . The partial TEF- $1 \alpha$ gene sequence of the isolate was submitted to GenBank (Accession No. KC831768). Pathogenicity and race were determined by inoculating 21 day old seedlings from lines with resistance to $F$. oxysporum f. sp. lycopersici race 1 , race 2 and race 3 . Wounded roots of 15 plants were dipped for $3 \mathrm{~min}$ in $50 \mathrm{ml}$ conidial suspension $\left(5 \times 10^{6}\right.$ microconidia/ml $)$ obtained from the isolate grown in potato dextrose broth and transplanted to 
Fig. 1 Phylogenetic tree of Fusarium oxysporum and related formae speciales produced using parsimony of part of the translation elongation factor $1 \alpha$ gene with $F$. graminearum as outgroup. Bootstrap values above $50 \%$ (percentages of 1,000 bootstrap replicates) are indicated in brackets above the branches of the tree. The isolate PPRI 10733 (KC831768), used in this study, has been deposited in the National Collections of Fungi, PPRI Collection, Plant Protection Research Institute, Agricultural Research Council, Pretoria, South Africa

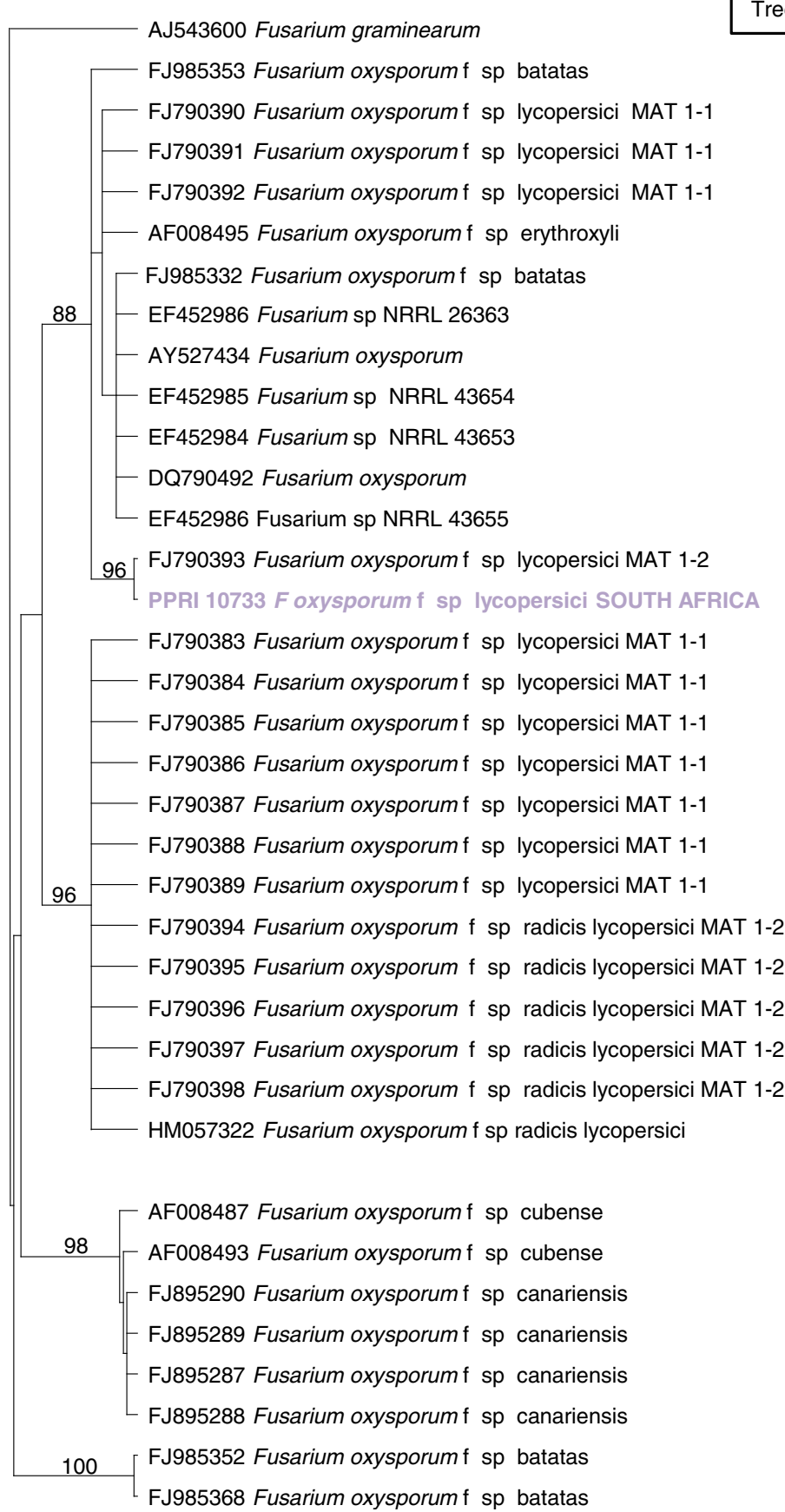

$\mathrm{g}_{1}=-0.605403$ $\mathrm{Cl}=0.9167$

$\mathrm{Rl}=0.9793$

Tree length $=36$ tubs containing pasteurized growing medium (peatmoss:perlite; $7: 3)$ amended with inoculated vermiculite $\left(5 \times 10^{6}\right.$ microconidia $/ \mathrm{ml}$ ) and maintained in a greenhouse at $24-26^{\circ} \mathrm{C}$ until symptom expression. Five seedlings of each line were wounded and transplanted to pasteurized growing medium and kept under the same conditions as inoculated plants. The plants were evaluated 20 days after inoculation using the following disease severity rating scale. 0-no external symptoms of wilting, yellowing and/or stunting, no vascular discoloration, 1-no external symptoms, isolated points of discoloration in vascular tissue, 2-discoloration up to cotyledonary node, 3-no external symptoms, staining beyond cotyledonary node, 4-wilting, yellowing and severe stunting, discoloration of vascular tissue beyond cotyledonary node, 5-complete death. A mean disease severity rate of 4 was observed for the inoculated, race 1 and race 2 resistant lines. A mean disease severity rate of 0 was 
observed for the inoculated race 3 resistant plants. A mean disease severity rate of 0 was observed for the un-inoculated control plants. These tests were performed twice in the same manner as stated above.

The causal agent was re-isolated from diseased material to prove Koch's postulates. This is the first report of Fusarium oxysporum f. sp. lycopersici race 3 on tomato in South Africa.

\section{References}

Armstrong GM, Armstrong JK (1981) Fusarium . Disease, Biology, and Taxonomy. In: Nelson PE, Toussoun TA, Cook RJ (eds) Fusarium species: An illustrated manual for identification. Pennsylvania State University Press, University Park, pp 391-399

Di Pietro A, Madrid MP, Caracuel Z, Delgado-Jarana J, Roncero MIG (2003) Fusarium oxysporum: Exploring the molecular arsenal of a vascular wilt fungus. Mol Plant Pathol 4:315-326
Geiser DM, Jimenez-Gasco MM, Kang S, Makalowska I, Veeraraghavan N, Ward TJ, Zhang N, Kuldau GA, O'Donnell K (2004) FUSARIUM-ID v. 1.0: A DNA sequence database for identifying Fusarium. Eur J Plant Pathol 110:473-479

Leslie JF, Summerell BA (2006) The Fusarium laboratory manual. Blackwell Publishing, Oxford

Michielse CB, Rep M (2009) Pathogen profile update: Fusarium oxysporum. Molecular Plantpathology 10:311-324

Nelson PE, Tousson TA, Marasas WFO (1983) Fusarium species: An illustrated manual for identification. Pennsylvania State University Press, University Park

O’Donnell K, Kistler HC, Cigelnik E, Ploetz RC (1996) Multiple evolutionary origins of the fungus causing Panama disease of banana: Concordant evidence from nuclear and mitochondrial gene genealogies. Proc Natl Acad Sci U S A 95:2044-2049

O’Donnell K, Humber RA, Geiser DM, Kang S, Park B, Robert VARG, Crous PW, Johnston PR, Aoki T, Rooney AP, Rehner SA (2012) Phylogenetic diversity of insecticolous fusaria inferred from multilocus DNA sequence data and their molecular identification via FUSARIUM-ID and Fusarium MLST. Mycologia 104:427-445 